\title{
A devastação anti-ecológica do capital
}

Gilberto Felisberto Vasconcellos*

\section{Resumo}

Este artigo está centrado na ideia de que a acumulação de capital é anti-ecológica. O lucro é incompatível com a preservação da natureza. A crise desta, consubstanciada atualmente no aquecimento global, é ocasionada não por motivos naturais, mas sim por imperativos de um modo social e econômico de produção, que tem feito uso desde a revolução industrial dos combustíveis fósseis: carvão mineral e petróleo. A alternativa para a devastação ecológica encontra-se na produção da energia vegetal localizada sobretudo nas regiões intertropicais, sendo o Brasil o maior país tropical do planeta.

Palavras-chave: Energia; Economia-Política; Geografia; Trópico.

The anti-ecological devastation of the capital

\begin{abstract}
This article is centered on the idea that capital accumulation is antiecological. The profit is incompatible with the preservation of nature. The crisis of this, currently embodied in the global warming, is caused not by natural reasons, but rather for imperative of a social and economic mode of production, which has used since the industrial revolution of fossil fuels: oil and mineral coal. The alternative to the ecological devastation is in the production of

* Professor Titular da Universidade Federal de Juiz de Fora (felipexls@hotmail.com).
\end{abstract}

Geosul, Florianópolis, v. 32, n. 63, p 249-268, jan./abr. 2017 
VASCONCELLOS, G.F. A devastação anti-ecológica do capital.

plants located mainly in the intertropical regions, with Brazil being the largest tropical country in the world.

Key words: Energy; Political economy; Geography; Tropic.

A causa do aquecimento do planeta, que é sistematicamente elidida pela mídia financiada pelas grandes multinacionais do petróleo, é o dióxido de carbono lançado na atmosfera. Com isso já se alertou muitas vezes para o risco das cidades serem submergidas com o derretimento das geleiras e o aumento do nível dos mares. Para enfrentar essa questão ambiental, recorrem-se às medidas imediatas e superficiais como substituir o automóvel pela bicicleta e a lâmpada incandescente pela fosforescente. Essas medidas são paliativas e não evidenciam a raiz do problema.

É impossível suprimir os cataclismos ambientais com tecnologia, seguramente a contradição entre natureza e humanidade não será de solucionada por artefatos tecnológicos fabricados pelos países centrais do capitalismo, como Estados Unidos, Japão e Alemanha. A mídia é enganadora quando divulga que a invenção tecnológica por si só é capaz de resolver os problemas ambientais causados pelo capitalismo monopolista, ocultando o regime de propriedade e sua organização social. Como é que se produz e com quê se produz e qual é a natureza da produção da vida, isso tudo é secundário; o importante é a tecnologia. O fetichismo tecnológico encobre a existência do antagonismo entre acumulação de capital e ecologia; na verdade, o que é bom para acumulação de capital não é bom para o meio ambiente. Poder-se-ia dizer que é impossível harmonizar a sociedade capitalista com a natureza. A expansão capitalista traz em seu horizonte a morte das espécies humanas e animais, enfim, ou o capitalismo é superado, ou a humanidade corre o risco de não sobreviver, de modo que a contradição fundamental é entre capital e natureza, pois o capital é essencialmente anti-ecológico. 
VASCONCELLOS, G.F. A devastação anti-ecológica do capital.

A destruição da natureza é feita por um sistema socioeconômico, o sistema do lucro, ou seja, o capitalismo. Mesmo que haja uma redução drástica na emissão de gás carbônico, isso não significa que o problema do aquecimento global será resolvido. Muitos cientistas diante do aquecimento global já alertaram acerca de um mundo onde não haverá mais gelo com o derretimento das calotas polares.

O combustível fóssil foi utilizado como a forma energética do capitalismo durante a revolução industrial, o capitalismo se fez com a mina concentrada de carvão mineral e, depois, com o poço de petróleo. A matriz energética fóssil tem que ser eliminada, basta ver a estatística: de 2000 a 2004 houve 400 catástrofes climáticas. No caso da China sabemos que há um abuso na utilização de carvão mineral para produzir eletricidade. "O socialismo de mercado" chinês precisa interromper urgentemente a emissão de dióxido de carbono.

O capitalismo não pode mais se desenvolver em detrimento da natureza, qualquer que seja o ritmo de acumulação. Karl Marx viveu a transição da lenha para o carvão mineral, mas não viu as consequências dos combustíveis fosseis no desequilíbrio da biosfera, e foi Marx quem disse que a natureza é o corpo do homem. Sublinhe-se que em nosso próprio sangue está o sinal da degradação ecológica, assim como a urina está contaminada pela petroquímica das multinacionais.

A lógica mercantil capitalista produz o câncer no homem. Muita gente raciocina de maneira equivocada a exemplo do seguinte: posto que a expansão do fóssil ocorre em escala vertiginosa, por que não estacionar a expansão capitalista? Acontece porém que a ideia de um capitalismo estacionário é uma fantasia sem nenhuma base na realidade. A acumulação de capital não pode estacionar, assim como é inconcebível a existência de um capitalismo sem lucro. O capital não pode ser contido em sua permanente auto-expansão, e não importa se isso danifica a natureza, pois o lema do capitalismo é "crescer ou morrer". Os ideólogos da economia verde alardeiam que é possível ter um meio 
VASCONCELLOS, G.F. A devastação anti-ecológica do capital.

ambiente saudável no capitalismo, ou seja, seria possível conciliar o lucro com o equilíbrio ambiental.

O trópico é o grande ausente na abordagem marxista sobre energia e ecologia. Os intelectuais europeus e norteamericanos não concebem a utilização da biomassa a não ser inserida na economia de escala multinacional, eles não consideram que é possível produzir a energia vegetal da biomassa em microdestilarias de álcool. Os cientistas sociais ficam atônitos com a afirmação do físico J.W. Bautista Vidal, segundo a qual o sol incidindo nas regiões tropicais equivale por dia à energia gerada por $300 \mathrm{mil}$ usinas Itaipu. A incidência solar na planície amazônica corresponde em potência energética a 6 milhões de bombas atômicas lançadas sobre Hiroshima. Convém lembrar do que foi anunciado sobre o babaçu pela Escola Brasileira da Biomassa, da qual fizeram parte Bautista Vidal e o geólogo Marcelo Guimarães. É que o babaçu do Maranhão equivale a uma petrolífera Arábia Saudita, sem mencionar o elevado potencial do dendê e da mamona. Daí infere-se que o Brasil não deveria ficar atrelado ao petróleo, pois isso pode trazer o suicídio da nação. Não nos esqueçamos que o petróleo foi o ingrediente fundamental na montagem da dívida externa. Acrescente-se que o patrimônio mineral brasileiro é riquíssimo. Só o metal nióbio de Araxá faz a festa da indústria informática no Vale do Silício e no Japão, país que carece de petróleo e minério.

Os EUA querem punir o Irã por causa da arma nuclear, isso é uma falácia, pois estão de olho é no petróleo. Israel há trinta anos produz arma nuclear e os EUA silenciam a respeito. O jogo nuclear é cínico e cheio de artimanhas, ainda mais com a crise financeira que começou em 2007, chamada de "a grande estagnação". Há quem diga também que a China é quem vai salvar o capitalismo, o problema é que a China hoje é uma sociedade extremamente desigual e diferente do que era na época de Mao Tse Tung. A questão ecológica é gravíssima devido à queima do carvão mineral. A China é a grande emissora de dióxido de carbono em sua 
VASCONCELLOS, G.F. A devastação anti-ecológica do capital.

agricultura com fazendas enormes utilizando fertilizantes derivados do petróleo.

A questão energética não pode ser pensada senão do ponto de vista mundial. As ideias de Bautista Vidal e Marcelo Guimarães encontram dificuldade de se materializar se o trópico permanecer sob regime capitalista, mas isso no entanto não quer dizer que as brechas dentro do sistema capitalista não devam ser aproveitadas. A dificuldade é que os cientistas brasileiros não ficaram imunes ao preconceito em relação ao trópico que foi inoculado pelo colonialismo fóssil das nações hegemônicas. É difícil romper com essa alienação energética. Haja vista a discussão equivocada sobre a contradição entre energia vegetal e comida. Uma coisa é reconhecer o monopólio da semente, $41 \%$ da produção é controlada mundialmente pela Monsanto, Dupont, Cargil e outras corporações estrangeiras. A agricultura familiar de biomassa é diferente da agricultura baseada em fertilizantes sintéticos, então a comida para o povo (não para o lucro) não pode ser feita com adubo nitrogenado. $O$ capital quer mudar a matriz energética do petróleo para o vegetal sem mexer no sistema de propriedade, oferecendo aos usineiros e multinacionais a terra para ser plantada um novo combustível visando à exportação. $\mathrm{O}$ imperialismo ambiciona converter os países subdesenvolvidos (situados nos trópicos) em exportadores de biocombustíveis. Hoje trinta milhões de hectares estão sendo comprados pelas corporações multinacionais na África.

\section{Ecologia e capitalismo}

$\mathrm{Na}$ devastação do meio ambiente o capitalismo é o grande responsável com emissão de gases fósseis e destruição das florestas, sem mencionar que a agricultura no mundo inteiro é feita com fertilizantes artificiais, aumentando assim o CO2 lançado na atmosfera. Ainda que seja interrompida a emissão de gases fósseis o efeito estufa não será automaticamente eliminado, pois o $\mathrm{CO} 2$ permanece durante muito tempo na atmosfera. Os mares e as 
VASCONCELLOS, G.F. A devastação anti-ecológica do capital.

florestas não estão danificados por "desastres naturais", mas pela lógica capitalista do lucro. Os fertilizantes tóxicos do agrobusiness contaminam lagos e rios contribuindo para a desertificação. Os climatólogos têm advertido que o fundo dos oceanos absorve muita luz do sol e as espécies estão morrendo. A água ácida elimina a comida dos peixes que estão sendo medicados com antibióticos.

O desastre ambiental concerne a todos os países: ar, água, terra e comida. Os mares engolindo as ilhas e eliminando as regiões costeiras, acidificando o oceano devido às emissões de dióxido de carbono. A morte envenenada da natureza significa o fim da aventura humana na terra.

A agricultura com economia de escala e monocultura depende do fertilizante sintético, de que resultam a erosão do solo, o esgotamento das reservas nutricientes, a contaminação química, os pesticidas e os nitratos usados na produção da comida. O agronegócio elimina as pequenas famílias na roça. Ao contrário do que a mídia divulga, a biotecnologia não dá jeito na degradação ambiental. A "biotecnologia" é uma mistificação patrocinada pela Monsanto e seu pesticida "round up".

Quanto à relação entre ecologia e capitalismo (a perda de nutrientes e a fertilidade do solo), cumpre lembrar que a agricultura (incluindo o adubo) sempre foi um problema no capitalismo. $\mathrm{Na}$ Inglaterra, antes do fertilizante sintético, usava-se osso e guano, que é excremento de passarinho importado da América Latina. Com a separação campo e cidade, a depredação da natureza aumentou, persistiu o antagonismo entre capital e trabalho, mas hoje existem as contradições ambientais à acumulação de capital. As contradições de classe e ecológicas estão imbricadas, mas isso não quer dizer que o capitalismo será destruído pelas contradições ecológicas. Uma coisa é certa: não há possibilidade de preservar a natureza no sistema capitalista. Mais do que afetar a acumulação de capital, a degradação ecológica coloca em risco a sobrevivência da humanidade. A natureza não existe para o homem habitar nela, e hoje o grande desafio é o aquecimento global. Sem combustível não pode haver acumulação de capital, o adubo feito pelo petróleo 
VASCONCELLOS, G.F. A devastação anti-ecológica do capital.

empobrece o solo, e nenhuma tecnologia é capaz de limpar a natureza. O capitalismo foi visto por Marx como um sistema hostil à natureza, mas não tinha atingido a dimensão catastrófica dos dias atuais.

A retórica dos teóricos verdes lamenta a degradação ambiental, mas não condena as suas causas. Em Kyoto foi repetido varias vezes que os países ricos usam maior quantidade de combustíveis fósseis em suas economias, mas as nações desenvolvidas não vão interromper a emissão de gases fósseis. É impossível existir capitalismo sem toxina, a química sintética é um produto da economia fóssil capitalista, a indústria do plástico e do pesticida são cancerígenas. A agricultura está baseada nas sementes das multinacionais que, por sua vez, são produtoras dos fármacos e proprietárias das patentes.

Surgido depois da Segunda Guerra Mundial, o agronegócio degradou o ambiente com os pesticidas e herbicidas. A água e o ar foram contaminados junto com a erosão do solo e o declínio das pequenas cidades, como aconteceu nos EUA durante a década de 60, mas a natureza não se degradou por si mesma, a crise da natureza não é autoengendrada. A crise da natureza é provocada por um sistema de relações sociais. Ingenuidade ou má fé é supor que o capital poderá chegar a um estágio de ecoeficiência. Assim, a solução é para além do capitalismo e da petroquímica. Esta não pode continuar como sendo o combustível de um regime socialista. O combustível fóssil não perde sua nocividade com o socialismo; afinal, é impossível resolver o problema do clima sem interromper os gases fósseis. Nenhum invento tecnológico é capaz de sequestrar o dióxido de carbono da atmosfera.

De 1990 em diante conglomerados multinacionais estão comprando enormes extensões de terra, ou associando-se aos latifúndios cujos proprietários são brasileiros. O objetivo a curto e médio prazo é produzir álcool-combustível e óleos vegetais destinados à exportação. A compra do território brasileiro por estrangeiros é o fato mais importante deste século do ponto de vista econômico e ecológico. 
VASCONCELLOS, G.F. A devastação anti-ecológica do capital.

Agredida pelo lucro capitalista com combustíveis fosseis, a natureza está em perigo. Surpresa é a vida deixar de existir antes que sucumba o capitalismo. Este está compelido a expandir-se, mas a progressiva acumulação de capital entra em contradição com os limitados recursos naturais do planeta. O mundo inteiro quer livrar-se da queima poluidora de carvão mineral, petróleo e gás, mas o problema é que o capitalismo não pode deixar de utilizá-los.

À basilar contradição do capitalismo radicada na socialização versus apropriação privada, cuja expressão é a contraposição burguês-proletário, acrescentem-se os danos ecológicos causados pela acumulação fóssil de capital. Essas duas contradições se juntam neste século XXI, mas a segunda é que constitui sem dúvida a novidade. Em sociedades pré-capitalistas houve também depredações ecológicas, mas foram confinadas ao âmbito local. Hoje o que existe é o aquecimento globalizado do planeta, cuja principal causa é a existência de uma economia impulsionada por combustíveis poluidores da atmosfera e que são esgotáveis com reservas cada vez mais escassas para atenderem as demandas da indústria.

A história do capitalismo desde 1800 com a revolução industrial é indissociável do combustível fóssil. Os países avançados são os que mais consomem petróleo, assim não é por acaso que a disputa pelas suas fontes e reservas constitui o principal motivo das guerras a partir da metade do século XX. A economia mundial depende desse combustível, de modo que sua exaustão (pouco importa se daqui a 20, 30, 40 anos) coloca todos os países em uma situação dramática.

O capitalismo é um sistema baseado na propriedade privada dos meios de produção (que contrata por salário a força de trabalho), e não pelo combustível de que se utiliza para acumulação de capital. O capitalismo mercantil antecede ao uso de carvão mineral e petróleo, as navegações e a descoberta da América não foram impulsionadas por esses combustíveis, e sim pela lenha e pelo vento, que são formas dispersas de energia; no entanto a concentração energética com a mina de carvão mineral 
VASCONCELLOS, G.F. A devastação anti-ecológica do capital.

foi o ponto de partida da consolidação do capitalismo industrial. Do ponto de vista da apropriação privada da riqueza produzida pela força de trabalho, o capitalismo continua o mesmo, mercantil, industrial, movido pela lenha, carvão mineral, petróleo, nuclear, força muscular, força motriz, força física não muscular, eólica, queda d'água, vapor, eletricidade. Isso tudo não define $o$ capitalismo como modo de produção, assim como a máquina não altera as relações sociais, dizia Álvaro Vieira Pinto em seu livro $O$ Conceito de Tecnologia, que é um verdadeiro tratado sobre o fetichismo tecnológico. Nesta nossa época em que a ideologia dominante converte a invenção tecnológica no "elixir das bruxas", capaz de resolver por si só todos os problemas da humanidade, sem que seja alterada a estrutura social capitalista. $O$ Conceito de Tecnologia foi escrito contra a formulação de que a técnica faz a história, como se a ciência e a técnica decidissem o destino do homem. Álvaro Vieira Pinto não concordou em periodizar a história sob o critério dos instrumentos ou máquinas utilizados, nem pelas formas ou fontes de energia. Segundo o filósofo, a abordagem materialista deveria focalizar os modos de produção dos regimes sociais. Deu como exemplo o fato de que a condição de escravo foi o elemento decisivo, e não o instrumento com o qual trabalhava, assim como seria um equívoco afirmar que a humanidade está ingressando em um novo período histórico por causa da energia nuclear ou da cibernética. Por conseguinte, é uma falácia repetida tantas vezes pelo poder imperialista que estamos vivendo em uma excepcional era tecnológica. Nunca existiu época que fosse a-tecnológica, é impossível conceber o homem sem técnica. O elemento primário na produção da existência, o que cria a historia, é o ato social do trabalho, e não a descoberta de uma nova fonte de energia e sua utilização tecnológica.

\section{Geografia dos trópicos}

O movimento dos trabalhadores sem terra poderia ser uma resistência ecológica a favor da produção de energia vegetal em 
VASCONCELLOS, G.F. A devastação anti-ecológica do capital.

pequenas propriedades, mas a direção do MST ainda não tomou conhecimento do que significa o trópico na fase pós-petróleo. $\mathrm{O}$ MST tem uma concepção colonizada da agricultura; afinal, não podemos esperar de marxistas europeus e americanos uma reflexão sobre o que nós somos como espaço e tempo.

O potencial da biomassa só vai se efetivar com o socialismo, mas não podemos assumir uma posição escatológica, deixando tudo para o futuro. A enfermidade ecológica exige que se pense na atmosfera e sua relação com o adubo. A economia de escala capitalista é fecundada por um fertilizante sintético feito de petróleo, cuja contaminação química destrói as plantas, polui a água e danifica o solo. Por isso é que a comida está provocando câncer. É mistificação falar em capitalismo ecológico e capitalismo natural, ou que possa existir justiça ambiental sob o comando do latifúndio e das multinacionais.

Os quatro séculos de latifúndio e escravidão demonizaram a cana-de-açúcar, separando-a das relações sociais. Ela foi considerada de maneira abstrata como sendo uma planta antiecológica. Do século XVI em diante a cana-de-açúcar foi a planta latifundiária escravagista, por isso contribuiu para produzir a fome, a seca e a erosão do solo eliminando os nutrientes da terra. Isso constitui uma irrefutável verdade tendo em mira os malefícios antiecológicos decorrentes da monocultura da cana-de-açúcar destinada à exportação colonial, mas isso não pode de modo algum ser atribuído às qualidades naturais dessa gramínea. O que arruinou o nordeste brasileiro não foi a cana-de-açúcar, mas a estrutura latifundiária colonial que a plantou, assim associar a cana-deaçúcar com o latifúndio tornou-se um lugar comum na historiografia, a cana-de-açúcar para ser plantada não precisa de grande extensão de terra. A equação latifúndio = cana-de-açúcar foi uma contingência histórica, o que não quer dizer que ela não possa combinar com a policultura e a pequena propriedade. A cana-de-açúcar é o que o regime social faz dela, podendo ser (e seguramente será) a planta do socialismo, a base do socialismo solar, o socialismo doce, digamos assim. É impossível convencer 
VASCONCELLOS, G.F. A devastação anti-ecológica do capital.

os países ricos (beberrões de combustíveis fósseis) que devem parar com isso, ainda que as multinacionais oportunisticamente estejam divulgando que temos de ir além do petróleo. Claro que a burguesia também se preocupa com a biosfera e com o aquecimento global, porque a crise da natureza envolve também a sobrevivência dos ricos. Os pobres sofrem mais com a devastação ambiental, mas os ricos também não escapam do aquecimento global, pois o ar condicionado não é a saída.

$\mathrm{Na}$ acumulação de capital o petróleo serviu como uma forma de energia concentrada. Houve sintonia entre o fóssil (propriedades físicas) e acumulação capitalista. Eletricidade. Motor elétrico. Motor a combustão. Iluminação das cidades. A lógica do lucro ficou independente do espaço e do tempo depois da utilização do petróleo. O capitalismo não poderia ter se desenvolvido sem essa energia fóssil. A vida no entanto é impulsionada pela radiação solar. Falta oxigênio no petróleo. Desde 1950 já anunciavam que o petróleo estava chegando ao fim.

Durante a década de 70 os cientistas Bautista Vidal e Marcelo Guimarães chamaram a atenção para a geopolítica energética do imperialismo diante do fim do petróleo, da depredação ecológica e da usurpação do território pela posse e controle da energia vegetal. Os porta-vozes do poder petrolífero mundial anunciavam que o combustível fóssil não iria nunca se acabar, portanto não haveria necessidade de buscar a fonte vegetal de energia, a qual era considerada de potência inferior comparada ao petróleo, assim seria impossível satisfazer as demandas da sociedade industrial com os combustíveis vegetais.

No passado os teóricos das nações hegemônicas afirmavam que não havia petróleo no Brasil, hoje se desqualifica o álcool como combustível para que o país fique atrelado ao petróleo. Não foram poucos os dirigentes da Petrobrás que estiveram convencidos acerca da inviabilidade da biomassa. Por seu turno, a esquerda apontava que o álcool não passava de um instrumento dos latifundiários em aliança com a indústria automobilística. É claro que o programa Pro-Álcool não alterou a estrutura latifundiária e o 
VASCONCELLOS, G.F. A devastação anti-ecológica do capital.

poder dos usineiros, que remonta à época colonial com a usina de açúcar que liquidou com os banguês e as pequenas propriedades. É um fato histórico incontestável que a cana-de-açúcar (inicialmente no Engenho e, depois, na usina a vapor) foi a planta que fez a acumulação de capital desde os tempos dos donatários. Sob esse ângulo (da produção de açúcar à produção de álcool), permanece a mesma estrutura social latifundiária com a classe industrial dos usineiros associadas cada vez mais ao capital monopolista estrangeiro na produção, pois na esfera da circulação e dos mercados consumidores a lavoura açucareira sempre foi uma empresa capitalista internacionalizada. O problema é a tendência em demonizar a cana-de-açúcar do latifúndio, como se a produção de álcool combustível fosse impossível no regime social de pequenas propriedades. Ora, é o caso de perguntar: a cana-deaçúcar (com os seus derivados) não pode ser a planta que fundamentará a construção do socialismo? É preciso acrescentar que o marxismo, originário dos países frios do planeta, ainda não atentou para a natureza dos trópicos.

Com a interrupção do Pro-Álcool e a privatização do território (compra de enormes extensões de terra por empresas estrangeiras), simultaneamente ocorreram as sucessivas catástrofes ambientais em escala mundial decorrentes da queima dos combustíveis fósseis. Atualmente as nações hegemônicas começam a enaltecer as energias limpas e renováveis. Da década de 90 em diante o álcool passou a ser denominado por etanol. Os países do hemisfério Norte, carentes de incidência solar, encontram-se na seguinte encruzilhada: as poucas reservas de petróleo que existem estão interditadas por motivos ecológicos, sobretudo por causa da mudança climática, ou seja, o aquecimento do clima.

Os cientistas e climatólogos da NASA já alertaram que é urgente interromper a queima de carvão mineral e de petróleo, caso contrário o planeta entrará em colapso. Se o capitalismo é antiecológico, por outro lado, o socialismo não poderá fazer uso da matriz fóssil. Isso significa que o socialismo tem de ser necessariamente solar, socialismo do sol. E, nesse aspecto, a geografia 
VASCONCELLOS, G.F. A devastação anti-ecológica do capital.

assume função determinante, pois é nas regiões tropicais que a energia solar é fixada nas plantas através da fotossíntese. A planta armazenadora da energia eletromagnética vinda do sol é a condição da vida no planeta. A objeção feita à biomassa (a contradição entre combustível e alimento) não procede, porque é possível plantar conjuntamente energia e comida na terra, mas para isso é necessário eliminar a grande propriedade monocultora. Se a energia vegetal for acionada por capital monopolista, eliminará seu potencial descentralizante, democrático e ecologicamente limpo. Assim, a energia vegetal aprofundará o subdesenvolvimento, a grande propriedade desempregadora de mão-de-obra exportará energia vegetal com economia de escala e concentração de produção.

Quando se fala de álcool e óleos vegetais, é preciso saber em que lugar são produzidos e com quais plantas. Etanol feito de que planta? Com qual tipo de adubo? Etanol feito de milho é diferente de etanol feito de cana-de-açúcar. Há uma falsa antinomia entre agriculta de alimentos e produção de energia. Com 3\% de território dá para alimentar toda nossa população, além da criação de empregos e a valorização da mão-de-obra rural. Nos países frios e temperados o uso da biomassa só pode ser feito de maneira limitada por causa da baixa incidência solar.

\section{Ciência e natureza}

Se a estrutura conceitual das teorias que orientam as políticas econômicas tivessem por base os contextos naturais e sociais aos quais é aplicada e dos quais deveriam depender, poderíamos superar graves entraves que impedem ocorrer naturalmente o processo de desenvolvimento em nosso país. Uma pseudo teoria econômica exclusivamente financeira de moeda sem lastro e de controle externo anula a possibilidade de uma sociedade com desenvolvimento autônomo.

A desvalorização dos recursos naturais, ainda que estratégicos e escassos, contrapõe ao mundo concreto das riquezas a supervalorização do abstrato como suposto símbolo, a moeda de 
VASCONCELLOS, G.F. A devastação anti-ecológica do capital.

referência, manipulada por especuladores internacionais. O homem não cria nem destrói energia, que sempre se origina da natureza e sem a qual nada se move ou se transforma no mundo físico e que é definida pela ciência como a capacidade de produzir trabalho. Ademais, vive hoje a humanidade o fim da era dos combustíveis fósseis que promoveram o desenvolvimento de alguns países nos últimos dois séculos. $\mathrm{O}$ ocaso desses combustíveis está ocasionando conflitos na busca desesperada de domínio sobre as reservas de petróleo que restam. O fim dessas reservas é inexorável. Os combustíveis fósseis precisam ser substituídos por formas energéticas derivadas da biomassa, abundantes nas regiões tropicais com grande intensidade de radiação solar e água doce. A disponibilidade e o uso de fontes energéticas extensivas garantem o desenvolvimento e a manutenção das civilizações que ganham estabilidade e se mantêm de forma permanente quando essas fontes são renováveis.

O II Fórum Mundial de Energias Renováveis, realizado na cidade de Bohn, Alemanha, montou uma agenda essencial e inadiável que prevê mudanças na conceituação do processo de desenvolvimento, tendo em vista a reorientação da matriz energética mundial na direção das formas energéticas renováveis e limpas. Evidenciou o Fórum Mundial que o processo civilizatório assiste a modificação em seus rumos, em fase de acelerada crise do sistema energético global fóssil/nuclear. A elevação do preço do petróleo indica a exaustão dos combustíveis fósseis ante o aumento progressivo do consumo mundial de energia, especialmente em países emergentes com imensas populações como China e Índia. As mudanças de clima estão causando crescentes catástrofes com o uso contínuo dos combustíveis fósseis. A tecnologia nuclear não é de modo algum uma opção energética viável, a exemplo do que ocorreu com Chernobil.

Cumpre ressaltar que os combustíveis renováveis derivados da biomassa e os fósseis têm uma mesma origem na grande fonte primária de energia de nosso sistema planetário: o Sol. Trata-se do único reator a fusão nuclear, neste caso natural. Apesar de enormes esforços realizados, o reator a fusão nuclear não oferece qualquer 
VASCONCELLOS, G.F. A devastação anti-ecológica do capital.

perspectiva séria de ser construído pelo homem. A imensa quantidade de energia solar que incide por dia sobre o hemisfério da Terra equivale à energia de todas as reservas já descobertas ou avaliadas de petróleo. Essa radiação eletromagnética solar é captada pela fotossíntese das plantas formando os hidratos de carbono, a partir do anidrido carbônico do ar (CO2) e da água (H2O), por meio de uma reação química endotérmica, ou seja, com captação da energia solar.

Os hidratos de carbono assim formados nas plantas a partir da radiação solar - açúcares, amidos, óleos vegetais e celulose - são biomassas facilmente usadas ou convertidas em combustíveis diretamente usados nos motores, caldeiras e todo tipo de instrumentos de conversão energética. Seu período de formação extensivo é de dias, semanas ou meses. São os hidratos de carbono microscópicos que, depositados nos fundos de mares ou lagos, irão ao longo de centenas de milhões de anos formar os hidrocarbonetos pela perda do oxigênio. Esta é a razão por que os biocombustíveis derivados da biomassa são renováveis e o petróleo, carvão mineral e demais fósseis não são renováveis por exigirem eras geológicas para se formarem.

Pelos ingredientes necessários à sua formação, os hidratos de carbono - biomassa - para serem gerados em grande quantidade, exigem intensa radiação solar, ou seja, regiões tropicais e água abundante, especialmente nos trópicos úmidos. O Brasil é o único país de dimensões continentais detentor da maior quantidade de água no mundo. A civilização dos trópicos decorrente do predomínio, no futuro imediato da humanidade, das formas energéticas renováveis e limpas, têm no continente brasileiro o lócus paradigmático universal. Assim, em contrapartida à chamada civilização do petróleo, em fase de acentuado declínio, temos a civilização dos hidratos de carbono, permanente e limpa do ponto de vista ecológico.

O capitalismo universalizou a forma energética fóssil que põe em risco a sobrevivência da natureza. A perspectiva de um colapso do planeta (destruição do meio físico - terra, água, ar) surgiu na era do capital. O simpósio de Copenhague alertou sobre a urgência da humanidade sair da órbita do hidrocarboneto com os seus efeitos 
VASCONCELLOS, G.F. A devastação anti-ecológica do capital.

devastadores: chuva ácida em lagos e florestas, enfraquecimento da camada de ozônio, expansão dos desertos, contaminação das águas dos rios e oceanos por causa dos fertilizantes e pesticidas usados na agricultura. É ilusório o apelo humanitário para que haja imediatamente a redução da emissão de $\mathrm{CO} 2$ lançado na atmosfera. Imaginar uma boa vontade dos grandes empresários em diminuir sua emissão esbarra na implacável lei da acumulação de capital, de modo que os países industriais avançados reagem contra essa medida, pois o que move o capitalismo é a expansão do capital, não é zelar pela preservação do meio ambiente.

O subdesenvolvimento é miséria, falta de saneamento básico, lixo, cólera, dengue, febre amarela e destruição das florestas, mas o subdesenvolvimento não será eliminado com o aumento da produção econômica. $\mathrm{O}$ desenvolvimento não faz senão aumentar a pobreza. $\mathrm{E}$, sob esse aspecto, sem menosprezar a relação causal desenvolvimentosubdesenvolvimento, o que está em pauta é a coordenada geográfica, não a clivagem entre o sul e o norte, mas a distinção entre as regiões intertropicais e as regiões temperadas e frias.

A única alternativa de extrair energia e limpar ecologicamente o planeta encontra-se nas regiões intertropicais, dotadas de condições geográficas para produzirem extensivamente os combustíveis renováveis. É preciso deixar claro que não se trata de messianismo nacional, místico e salvacionista, e sim de um dado físico, concreto e geográfico. Nessas regiões intertropicais é que se situam os países pobres, nenhum até hoje eliminou o subdesenvolvimento. É tolice afirmar que o ocaso dos combustíveis fósseis traz a superação do imperialismo. A energia por si só não é determinante nos rumos da história. É indissociável a relação natureza e trabalho humano. A resposta equivocada à crise ecológica busca a solução na tecnologia, como se outro tipo de motor de automóvel ou de avião pudesse suprimir as causas do desastre ambiental com a agricultura de fertilizantes químico-fósseis e seus pesticidas cancerígenos. $\mathrm{O}$ aquecimento global é consequência de um sistema energético que abarca a comida e a saúde, ou seja, é ao mesmo tempo um processo de devastação gastro-alimentar produzida pelas corporações 
VASCONCELLOS, G.F. A devastação anti-ecológica do capital.

multinacionais. Quem produz o alimento, produz também o fármaco (remédio), de modo que o supermercado está indissoluvelmente conectado à drogaria.

A medida de caráter paliativo é diminuir a emissão de dióxido de carbono nos países industrialmente avançados, reduzir o uso do carvão mineral e do petróleo. Foi essa proposta que presidiu o Protocolo de Kyoto, mas a classe dominante norte-americana não lhe deu a menor importância, porque a economia dos Estados Unidos não pode prescindir dos combustíveis fosseis.

A economia política do automóvel foi o elemento chave da acumulação de capital, ancorada em três momentos cruciais: a máquina a vapor, a ferrovia e a indústria automobilística. Parvoíce seria solicitar às corporações multinacionais a redução de seus lucros com a progressiva diminuição do uso de combustíveis fósseis, como se o regime de acumulação de capital não fosse regida pela expansão sem limite.

A matriz fóssil será substituída por qual matriz energética? Só há duas alternativas: a nuclear ou a biomassa vegetal. A primeira é perigosa e inviável porque em cada usina nuclear está embutida uma bomba atômica. Ninguém sabe o que fazer com o resíduo radioativo, de modo que é um risco gerar eletricidade com plutônio. Isso pode ser o caminho para destruir a vida no planeta. Não resta senão a alternativa da fotossíntese, através da qual a energia do sol armazenada nas plantas (cana, girassol, mamona, dendê, babaçu) é uma fonte energética limpa, renovável, descentralizada e abundante nos trópicos. É com essa fonte energética que se processará a substituição da química poluente do hidrocarboneto para a química limpa do hidrato de carbono. É com o álcool e os óleos vegetais que a petroquímica poderá ser substituída pela alcoolquímica. A incidência do sol e a abundante água doce não bastam se não for alterado o regime social de trabalho e a grande propriedade.

A grande fazenda capitalista está vinculada ao petróleo e ao imperialismo transgênico; todavia o problema na história agrária do Brasil é que a cana de açúcar sempre fez parte do latifúndio 
VASCONCELLOS, G.F. A devastação anti-ecológica do capital.

monocultor e dos megausineiros e ex-escravocratas. Quarenta anos depois de descoberto o Brasil, o canavial trouxe o negro escravo para ser moído nas plantations. Do negro de Engenho ao bóia-fria da usina. A mão de obra como combustível humano produziu açúcar e enricou as metrópoles. Sempre visando a exportação. A cana-de-açúcar foi tida como nociva e reacionária. Isso foi responsável pela interpretação falaciosa do Pro-Álcool, como se este fosse um programa destinado a enriquecer os usineiros.

Marcelo Guimarães provou que a cana-de-açúcar pode ser a planta energética que fundamentará o socialismo nos trópicos. A estrutura agrária de pequenas propriedades com microdestilarias a álcool tendo por base o alambique árabe. Assim, o álcoolcombustível deixa de estar associado ao grande usineiro. A microdestilaria a álcool poderia converte-se em alavanca energética e tecnológica da agricultura familiar, a pequena propriedade produziria simultaneamente comida e energia. Esta é a novidade revolucionária na história da agricultura mundial: a terra produzindo ao mesmo tempo energia e comida.

Uma questão concernente à energia da biomassa no estágio pós-petróleo é se ela assumirá uma feição socialmente anti-povo ou um caráter libertário, que poderá ser o caminho para uma sociedade socialista no Brasil. Certamente uma produção energética para visando o bem-estar da maioria da população não pode ser alcançada sob o regime capitalista. O peixe grande papa o peixe pequeno, mas Marcelo Guimarães considerava que, no caso da biomassa, seria o inverso: o peixe pequeno papa o peixe grande. O pequeno produtor é mais viável economicamente do que o grande fazendeiro capitalista. Este é o salto evolutivo do processo histórico, cujo efeito é ocupar o território com brasileiros para impedir sua apropriação pelo imperialismo. Fazendo um balanço da Escola da Biomassa, não seria descabido afirmar que Bautista Vidal e Marcelo Guimarães realizaram uma interpretação do atraso e do subdesenvolvimento que tem por base um raciocínio de cunho geográfico e cósmico. 
VASCONCELLOS, G.F. A devastação anti-ecológica do capital.

\section{Referências bibliográficas}

BAUTISTA Vidal, J. W. Soberania e dignidade - raízes da sobrevivência. Petrópolis: Vozes, 1991.

BAUTISTA Vidal, J. W. A reconquista do Brasil. Rio de Janeiro: Espaço e Tempo, 1997.

BAUTISTA Vidal, J. W. Brasil - civilização suicida. Brasília: Star Print, 2000.

BAUTISTA, Vidal, J. W. \& VASCONCELLOS, G. F. Biomassa: A Eterna Energia do Futuro. São Paulo: SENAC, 2001.

. O Poder dos Trópicos. São Paulo: Casa Amarela, 1998.

. Dialética dos Trópicos. Brasília: Instituto do Sol, 2002.

. Petrobrás - um clarão na história. Brasília: Instituto do $\overline{\text { Sol, } 2001 .}$

FOSTER, John Bellamy. Epochal Crisis: converging economic \& ecological contradictions. New York: Monthly Review, 2013.

. The Planetary Crisis \& Late Soviet Ecology. New York: Monthly Review, 2015.

GUIMARÃES, Marcello. Autodesenvolvimento, o Brasil descobre a energia tropical. São Paulo: C.I, 1993.

GUIMARÃES, Marcello. Biomassa: energia dos trópicos em Minas Gerais. Belo Horizonte: UFMG, 2001.

HOLLEMAN, Hannah. Method in Ecological Marxism. New York: Monthly Review, 2015. 
VASCONCELLOS, G.F. A devastação anti-ecológica do capital.

MAGDOFF, Harry. Primitive, Accumulation e Imperialism. New York. Monthly Review, 2013.

MAGDOFF, Fred. Building an Ecologically Sound and Socially just economy, New York, Monthly Review, 2011.

MARX, Karl. O Capital. Paris: Pléiade, 1987.

MARX, Karl. Grundrisse. Rio de Janeiro: Boitempo, 2011.

MELLO, Antônio da Silva. Alimentação, instinto e cultura: perspectiva para uma vida mais feliz. Rio de Janeiro: José Olympio, 1943.

A superioridade do homem tropical. Rio de Janeiro: Civilização Brasileira, 1965.

MUMFORD, Lewis. The Culture of Cities. California: Harcout Brace Company, 1938.

PINTO, Álvaro Vieira. O conceito de tecnologia. São Paulo: $2^{\mathrm{a}}$. Ed. Contraponto, 2005.

VASCONCELLOS, G. F. A Salvação da Lavoura: Receita da Fartura para o Povo Brasileiro. São Paulo. Casa Amarela, 2001.

. Nossa vida de cada dia entre o supermercado e a drogaria. Juiz de Fora: UFJF, 2014.

Recebido em outubro de 2016

Aceito em novembro de 2016 